\title{
RE-EVALUATION OF LIFESPAN IN A NEOTROPICAL ORCHID: AN ELEVEN YEARS SURVEY
}

\author{
Eddie A. Rosa-Fuentes ${ }^{1} \&$ Raymond L. TREmblay ${ }^{1,2,3}$ \\ ${ }^{1}$ Department of Biology, 100 Rd. 908, University of Puerto Rico, Humacao, Puerto Rico, 00791 \\ ${ }^{2}$ Crest, Center for Applied Tropical Ecology and Conservation, PO Box 23341, University of Puerto Rico, \\ Río Piedras, Puerto Rico, 00931-3341 \\ ${ }^{3}$ Author for correspondence: raymond@hpcf.upr.edu
}

\section{KEY wORDS: epiphyte; Kaplan-Meier; Lepanthes; Puerto Rico}

Lifespan as a variable of the total survivorship period of individuals is infrequently studied. When studied it is often limited to investigation of the effect of some environmental variable on the lifespan of short lived morphological unit of the plant such as leaves or flowers. However, it is of crucial importance for determining the likelihood of survival of populations (Calder 1983, Tremblay, 2000) and should be part of any population viability analysis (PVA). Moreover evaluation of the mean (or medium) life and variance (or quartile) in lifespan is a variable of vital importance when considered for analyses of the likelihood of natural selection and genetic drift (Barrowclough \& Rockwell 1993, Merila \& Sheldon 2000, Crognier 2003). Many parameters are correlated with lifespan such as effective population size and lifetime reproductive success. Lifespan has a positive correlation with reproductive success, which is a consequence that individuals with longer lifespan have a higher probability of having offspring. Moreover, the larger the variance in lifespan the larger the variance in reproductive success and consequently effects the effective population size (Barrowclough \& Rockwell, 1993; Tremblay \& Ackerman, 2001).

Tremblay (2000) published a three years survey of lifespan in four species of Lepanthes including $L$. caritensis, however, after the three years survey most juveniles and adults were still alive (64 and 91\%, respectively), while most seedlings died during the survey period with only $25 \%$ still alive at the end of the survey. As a result, the survivorship curve only represented a partial life history of the species with a maximum possible lifespan as function of the survey period. Limited survey's can easily bias the results, which can suggest smaller mean and variance in the projected lifespan. A second preoccupation with the previously published paper is that the number of seedling surveyed was very small and consequently the estimates could have been affected from random mortality and survivorship and not be a good representation of the typical lifespan of this life stage. Thus in this survey we present a continuation of the survey of one of the species, Lepanthes caritensis Tremblay \& Ackerman and include a third population to the previously two studied with a total survey period of approximately eleven years for the first two populations.

Specifically we determined if mean and variance in lifespan from the surveyed populations and life stages are similar to the first 3 years survey. Secondly we evaluated if the survivorship among populations is equal. Thirdly, we investigated if the life stage and size (number of leaves) are determining factor in survivorship.

\section{Methods}

STUDY SYSTEM. Lepanthes caritensis is an endemic epiphytic, caespitose, and host specific orchid of 0.8 to $4.4 \mathrm{~cm}$ tall and its stems are appressed to the phorophyte. For description of the species and basic ecology refer to Tremblay \& Ackerman 1993, Tremblay 1997a, 1997b, and Tremblay et al., 1998.

STUdy AREA. This species occurs in a Subtropical Wet Forest of the Holdridge Life Zone System (Ewel \& Wetmore 1973) and is found in the municipality of Patillas, Puerto Rico in the Carite Forest (Tremblay \& Ackerman 1993). The plants are found at approximately $615 \mathrm{~m}$ asl (maximum of Puerto Rico is 1100 
TABLE 1. Sample size and sampled period for L. caritensis at three sites in the Carite Forest in Puerto Rico. Diameter at breast height $(\mathrm{DBH})$ of the phorophyte $(\mathrm{cm})$, and approximate sky visibility using a densiometer (\% open sky).

\begin{tabular}{lccccc} 
Population & Number of individuals & Month survey started & Month survey ended & DBH of tree & Sky Visibility \\
\hline 1 & 184 & September-94 & August-06 & 43 & 36.40 \\
\hline 2 & 111 & September-94 & August-06 & 45 & 32.24 \\
\hline 3 & 222 & May-02 & August-06 & 67 & 26.00 \\
\hline
\end{tabular}

asl) in an area that was apparently never logged. Annual mean temperature and rainfall are between 18 and $24^{\circ} \mathrm{C}$, and $2200 \mathrm{~mm}$ respectively (Ewel \& Wetmore 1973). Rain is more or less consistent throughout the year with a slight increase in the winter period.

DATA COLLECTION. We censored a total of 517 individuals on an irregular basis for over 11 years of which approximately six years were surveyed monthly (Table 1). We numbered all individuals with plastic tags as described in Tremblay 2000. At each survey period the number of leaves of each individual was counted and the stage of the individual was noted. Individuals from all populations where identified as seedlings, juveniles, and adults, where seedlings are small plants without lepanthiform sheets on the petioles of any of the leaves, juveniles are individuals with at least one lepanthiform sheath on the petiole without evidence of past or current reproduction, and adults encompassed individuals that are currently reproductive (active inflorescences) or have been in the past (inflorescences may persist for years after they have been active). The identification of plant stages follow previous studies (Tremblay 2000; Tremblay \& Hutchings 2003; and Rivera Gomez et al., 2006). The numbers of individuals alive at the end of the survey varied from 39 to 113 .

The individuals from the three populations are all found on older individuals of the tree Micropholis guyanensis (A. DC.) Pierre 1891 (Sapotaceae). Orchids are only found on the largest individuals of this species (Tremblay et al., 1998) and the three populations surveyed were on trees with DBH above 43 cm (Table 1).

INDICES MEASURED AND SOFTWARE USED. Comparison of the survivorship probability for all population and stages where evaluated by using proportional hazard or Cox's model, methods that lets you define models having failure time as the response variable with right-censoring and time-independent covariates. All tests including for multiple samples and the KaplanMeier's equation estimates were analyzed using the statistical softwares Statistica and JMP (Kaplan and Meier, 1958; Statsoft, 1994; survival analysis model; SAS Institute Inc., 2004, JMP v.5.1.2).

\section{Results}

General Pattern of Survivorship. Combining data from all three populations and stages the mean death rate per year in this specie is $5.1 \%$ per year. The mean lifespan (se) was estimated at $1388 \pm 74.2$ days (approx $3.8 \mathrm{yrs}$ ), and median lifespan at 846 days (approx. 2.3 yrs; Table 2, Fig.1).

DifFERENCES IN LIFESPAN AMONG POPULATIONS. Mean death rate per year by populations ranged from $4.1 \%$ to $18.0 \%$ per year. The two populations that were surveyed for 11 years had similar death rates while the third population had a higher death rate (Table 1, 2). The mean (s.e.) expected lifespan by population ranged from $739 \pm 39$ to $1544 \pm 119$ days (Table 3). We found a significant difference in the lifespan between all populations (Log-rank Test, $\chi^{2}=9.2846$, $\mathrm{df}=2, \mathrm{p}=0.0096$ ). Population two had the longest estimated lifespan while population three had the shortest estimated lifespan (Fig.2).

DifFERENCES IN LIFESPAN AMONG LIFE STAGES. Summing the individuals from the different stages of the three populations we found that the shortest mean lifespan (se) was observed in seedlings $(286 \pm 35.7)$ and the longest for adults $(2037.1 \pm 111.3$; Table 2 , Fig.3). The lifespan of the different stages were significantly different (Log -rank test, $\chi^{2}=260.2715$, df $=2, p<0.0001)$. Seedlings are more at risk from failing than juveniles or adults. 
TABLE 2. Total numbers of days surveyed, cumulative proportion surviving at the end of the survey, number of all individuals alive at the end of the survey, median, mean, and the standard error of the mean lifespan for all population and stages. (* = bias mean estimates as a result of censored observation (individuals still alive) in the final survey time, for this reason estimates are a lower bound for the true mean).

\begin{tabular}{|c|c|c|c|c|c|c|}
\hline Population & $\begin{array}{c}\text { Number of days } \\
\text { surveyed }\end{array}$ & $\left|\begin{array}{c}\text { Cumulative proportion } \\
\text { surviving (\%) }\end{array}\right|$ & $\left|\begin{array}{c}\text { Number of individuals } \\
\text { of the mean }\end{array}\right|$ & \begin{tabular}{|} 
Median survivorship \\
alive at the end of the survey
\end{tabular} & Mean & $\begin{array}{c}\text { Standard } \\
\text { error }\end{array}$ \\
\hline 1 & 4346 & 10.2 & 53 & 728 & $1544 *$ & 119 \\
\hline 2 & 4346 & 7.4 & 39 & 1246 & $1244^{*}$ & 114 \\
\hline 3 & 1567 & 26.7 & 113 & 653 & $739 *$ & 39 \\
\hline Combined & & 9.04 & 205 & 846 & $1388 *$ & 74 \\
\hline \multicolumn{7}{|l|}{ Stage } \\
\hline Seedling & & 7.9 & 32 & 154 & 287 & 36 \\
\hline Juvenile & & 1.2 & 79 & 688 & 783 & 71 \\
\hline Adult & & 17.2 & 94 & 1246 & $2037 *$ & 111 \\
\hline
\end{tabular}

THE EFFECT OF NUMBER OF LEAVES ON THE SURVIVORSHIP OF INDIVIDUALS. The number of leaves affected the survivorship within stage categories. The mean lifespan is dependent on the number of leaves in juveniles ranging from 539 to 1080 days and for adults we found that the mean lifespan (se) varies from 1653 to 2196 (Table 4). The median lifespan varied from 485 to 688 days for juveniles and 1120 to 1246 for adults, noting that the median for individuals with five or more leaves do not have an estimated value because more than $50 \%$ of individuals were still alive at the end of the 11 years survey.

\section{Discussion}

We found that in general that the mean lifespan of Lepanthes caritensis is approximately 3.8 years, which

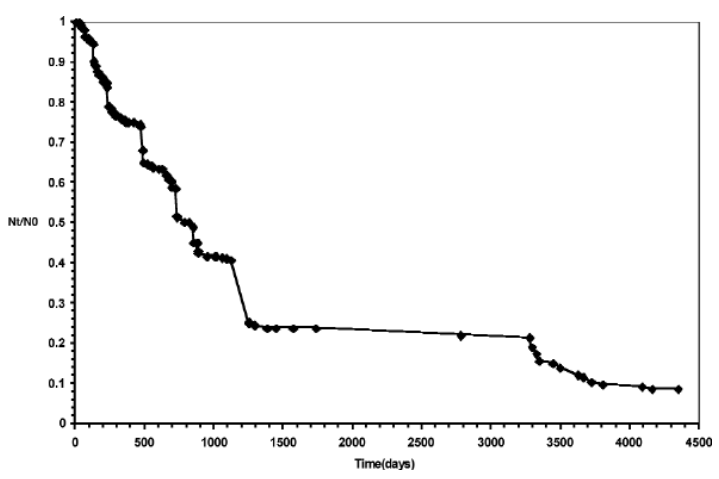

FIGURE 1. Survival curve of Lepanthes caritensis from an 11 yrs survey from 571 number of individuals. All populations and stages combined. $\mathrm{Nt} / \mathrm{No}=$ the number of individuals at time $t$ over the number of individual at the beginning of the survey. denotes that most of the individuals we've been studying had die in our 11 years survey. After the 3 yrs survey the lifespan for $L$. caritensis had been estimated at 1245 days (3.4 yrs; Tremblay 2000), which is clearly very close to the eleven yrs survey. The main effect on the length of the lifespan comes from the short lifespan of seedlings that influences the length of the species lifespan. The life history curve is a typical type two curve where the rate of change is fairly constant. Type one curve is for organisms living out their full physiological lifetime, for example Rhododendron maximum, and type three curve is for organisms experiencing high mortality and low survivorship in early stages like Spergula vernalis (Smith 1990).

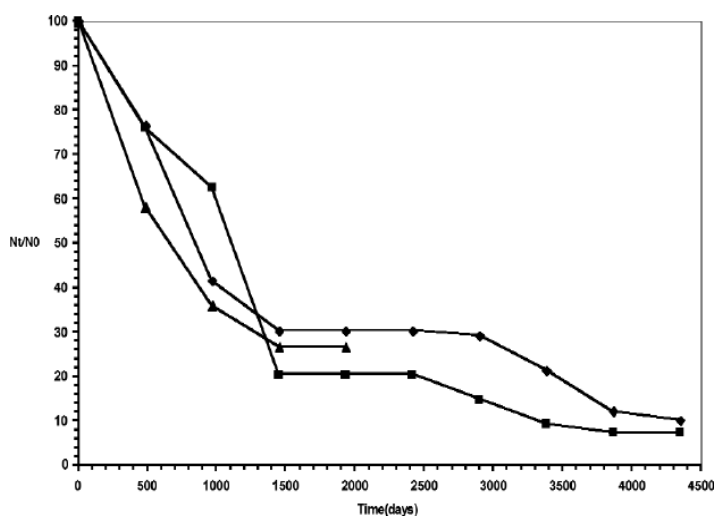

FIGURE 2. Cumulative proportion surviving for all populations of L. caritensis. Population 3 survey period was shorter. $\mathrm{Nt} / \mathrm{No}=$ the number of individuals at time $\mathrm{t}$ over the number of individual at the beginning of the survey. Diamonds $=$ pop. 1 , squares $=$ pop. 2 , triangles $=$ pop. 3 . 
TABLE 3. Percent death and mean lifespan (year) of Lepanthes caritensis and the sample size for estimating the parameter.

\begin{tabular}{|c|c|c|c|}
\hline Population & Percent death/year & Mean lifespan (yrs) & Sample Size \\
\hline 1 & 7.5 & 4.2 & 184 \\
\hline 2 & 7.9 & 3.4 & 111 \\
\hline 3 & 18.0 & 2.0 & 222 \\
\hline Combined & 7.7 & 3.8 & 517 \\
\hline \multicolumn{4}{|l|}{ Stages } \\
\hline Seedling & 45.3 & 0.8 & 96 \\
\hline Juvenile & 9.5 & 2.1 & 197 \\
\hline Adult & 7.0 & 5.6 & 224 \\
\hline
\end{tabular}

TABLE 4. The lifespan of individuals with varying number of leaves and life stages, mean lifespan (se) and median time for individuals by stage $(\mathrm{J}=$ Juveniles, $\mathrm{A}=$ Adults $) .(*=$ Bias estimate as some individuals still alive at the end of the survey).

\begin{tabular}{cccccc} 
Number of leaves & Stage (N) & Sample size & Mean & Standard Error & Median Time \\
\hline 1 & J & 38 & 539 & 62 & 688 \\
\hline 2 & J & 69 & 718 & 118 & 530 \\
\hline 3 & J & 65 & 877 & 125 & 728 \\
\hline 4 & J & 18 & 988 & 1080 & 485 \\
\hline$\geq 5$ & J & 7 & $1653^{*}$ & 285 & 1120 \\
\hline 1 & A & 34 & $1978^{*}$ & 189 & 1246 \\
\hline 2 & A & 68 & $1841^{*}$ & 178 & 1246 \\
\hline 3 & A & 63 & $2023^{*}$ & 277 & 1246 \\
\hline 4 & A & 30 & $2196^{*}$ & 265 & -
\end{tabular}

The behavioral pattern of survivorship between the three populations demonstrates that the two longest surveyed populations behave similarly while the newly added site had a shorter lifespan. In the previous study the median survivorship (1245 days) in the second population was the same as in this analysis (1246 days), while the median lifespan in population one was much lower (1245 days as compared to 728 days after the 11 yrs survey). The newly added population has a lower median lifespan as compared to population one (653 days). The reduce survivorship in this population could be influenced by the light availability; the proportion of visible sky in the third population is reduced, consequently higher shaded area (Table 2 ).

The life stages (seedling, juvenile or adult) are informative in determining the plant's lifespan. Seedlings have short lifespan as compared to juveniles (2.7 times longer lifespan than seedlings), while adults also differ from juveniles (2.6 times longer lifespan). In the previous survey estimates of lifespan were not available because too few individuals had perished during the survey period (Tremblay 2000). The increase survey period allowed for gathering estimates on the mean and median in lifespan of the different stages of this species.

The numbers of leaves in Lepanthes caritensis makes a significant difference in the plants lifespan. There is a correlation between lifespan and the number of leaves held by an individual. The number of leaves is related to the total leaf area and consequently these individuals are more likely to survive environmentally stressful period or partial herbivory (rare in this species).

The addition of 8 more years to the survey for estimating Lepanthes caritensis survivorship had little effect on the estimators of seedlings, however the addi- 


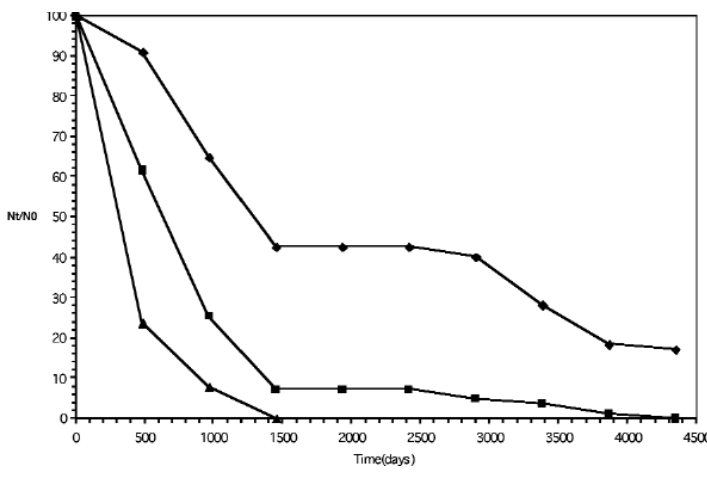

FIGURE 3- Cumulative proportion surviving for all three stages of $L$. caritensis. $\mathrm{Nt} / \mathrm{No}=$ the number of individuals at time $t$ over the number of individual at the beginning of the survey. Diamonds = Seedlings, squares $=$ Juveniles, triangles $=$ Adults.

tional survey suggest that juveniles and adults have a longer lifespan than predicted from the three year survey. Moreover, the number of leaves has a large impact of survivorship probabilities and thus could also be used a surrogate method for predicting lifespan instead of stages. Assuming constant mortality of adults at 7\% mortality per annum and a Weibull survivorship distribution it is expected that $10 \%$ of adults survive $12.2 \mathrm{yrs}$ and $1 \%$ will survive 21.5 yrs. Consequently a few individuals will likely have a very long lifespan as compared to most individuals and likely leave an excess of progeny as compared to most adults, resulting in a high variance in reproductive success.

ACKNOWLEDGMENT.We greatly appreciate the financial support from the Orchid Society of Arizona, which has supported the students for continued survey of the populations. We also would like to thank the individuals that help collect the data; Cristian Rosa, Nereida Fuentes, Jorge Merle, Juan Negrón, Francheska Ruiz, Frances Canino, and others.

\section{LITERATURE CITED}

Barrowclough, G.F. \& R.F. Rockwell 1993. Variance in Lifetime reproductive success: estimation based on demographic data. Amer. Nat. 141: 281-295.
Calder, W.A. 1983. Reproductive Success and Average Lifetime Natality. Oikos, 41: 288-289.

Crognier, E. 2003. Reproductive success: Which meaning? Am. J. Hum. Biol. 15: 253-260.

Ewell, J. \& J. Whitmore 1973. The ecological life zones of Puerto Rico and the U.S. Virgin Islands. Inst. Tropical Forestry of Puerto Rico Res. Paper ITF-18. $72 \mathrm{pp}$.

Kaplan, E.L. \& P. Meier 1958. Nonparametric estimation from incomplete observations." J. Am. Stat. Assoc. 53: 457-481.

Merila, J. \& B.C. Sheldon 2000. Lifetime reproductive success and heritability in nature. Am. Nat. 155: 301310.

Rivera Gómez, N., R.L. Tremblay \& E. MeléndezAckerman. 2006. Density dependent effects in a lithophytic and epiphytic orchid. Folia GeoBotanica 41: 107-120.

Smith, R.L. 1990. Ecology and field biology. HarperCollins Publishers Inc. $4^{\text {th }}$ edition. 341-347.

Tremblay, R.L. 1997a. Morphological variance among populations of three tropical orchids with restricted gene flow. Plant Species Biol. 12:85-96.

Tremblay, R.L. 1997b. Lepanthes caritensis, an endangered orchid: no sex, no future? Selbyana 18: 160-166.

Tremblay, R.L. 2000. Plant longevity in four species of Lepanthes (Pleurothallidinae: Orchidaceae). Lindleyana 15: 257-266.

Tremblay, R.L. \& J. D. Ackerman. 1993. A new species of Lepanthes from Puerto Rico. Brittonia 45: 339-342.

Tremblay, R. L. \& J. D. Ackerman. 2001. Gene flow and effective population size in Lepanthes (Orchidaceae): A Case for Genetic Drift. Biol. J. Linnean Soc. 72: 47 62.

Tremblay, R.L. \& M.J. Hutchings. 2003. Population dynamics in orchid conservation: a review of analytical methods based on the rare species Lepanthes eltoroensis. Pp. 183-204 in: K. Dixon, S. Kell, R. Barrett \& P. Cribb (eds.). Orchid Conservation. Natural History Publications (Borneo). Kota Kinabalu, Sabah, Malaysia. .

Tremblay, R.L., J. Zimmerman, L. Lebrón, P. Bayman, I. Sastre, F. Axelrod \& J. Alers-García. 1998. Host specificity and low reproductive success in the rare endemic Puerto Rican orchid Lepanthes caritensis (Orchidaceae). Biol. Cons. 85:297-304.

Eddie A. Rosa Fuentes is an undergraduate student of the Biology department at University of Puerto Rico in Humacao. His preparation is in Wildlife Management and Ecology. This is his first investigation experience and he is planning to continue his graduate studies in Conservation biology.

Raymond L. Tremblay is a professor of evolution, ecology and conservation biology at the University of Puerto Rico in Humacao and Rio Piedras. His interests include developing models for conservation of orchids in situ. 